\title{
Reversal of apoE4-Driven Brain Pathology and Behavioral Deficits by Bexarotene
}

\author{
Anat Boehm-Cagan and Daniel M. Michaelson \\ Department of the Neurobiology, The George S. Wise Faculty of Life Sciences, The Sagol School of Neuroscience, Tel Aviv University, Tel Aviv 69978, Israel
}

Apolipoprotein E4 (apoE4), the most prevalent genetic risk factor for Alzheimer's disease (AD), is less lipidated than its corresponding AD-benign form, apoE3, and it has been suggested that the pathological effects of apoE4 are mediated by lipid-related mechanisms. ATP-binding cassette transporters A1 and G1 (ABCA1 and ABCG1, respectively) are the most important apoE-lipidating proteins. The expression of these proteins, as well as that of apoE, is controlled by the transcription regulation retinoid X receptor (RXR)-liver X receptor (LXR) system. In the present study, we investigated the effects of the RXR agonist bexarotene on mRNA and protein levels of apoE, $A B C A 1$, and $A B C G 1$ in young, naive apoE3- and apoE4-targeted replacement mice and assessed the extent to which this reverses the apoE4-driven pathological phenotype. This investigation reveled that bexarotene increases the mRNA and protein levels of ABCA1 and ABCG1 in hippocampal neurons, but has no effect on the corresponding levels of apoE. These findings were associated with reversal of the lipidation deficiency of apoE4 and of the cognitive impairments of apoE4 mice in several tests. Furthermore, bexarotene reversed the apoE4-driven accumulation of $\mathrm{A} \beta 42$ and hyperphosphorylated tau in hippocampal neurons, as well as the apoE4-induced reduction in the levels of the presynaptic marker vesicular glutamatergic transporter 1 (VGluT1). In conclusion, the results show that treatment of apoE4 mice with the RXR agonist bexarotene reverses the apoE4-induced cognitive and neuronal impairments in vivo and suggest that this is due to reversal of the lipidation deficiency of apoE4. This puts forward the possibility that RXR activation and increased levels of $\mathrm{ABCA} 1$ and $\mathrm{ABCG1}$ could be useful in the treatment of human apoE4 carriers.

Key words: ABCA1; ABCG1; Alzheimer's disease; apoE-targeted mice; ApoE4; bexarotene

\section{Introduction}

Genetic studies of Alzheimer's disease (AD) revealed allelic segregation of the apoE gene to sporadic $\mathrm{AD}$ and to families with a higher risk of late-onset AD (Corder et al., 1993; Saunders et al., 1993; Roses, 1996). There are three major alleles of apoE, termed $\mathrm{E} 2$ (apoE2), apoE3, and apoE4, of which apoE4 is the $\mathrm{AD}$ risk factor.

It had been suggested that the pathological effects of apoE4 are mediated by lipid-related mechanisms (Puglielli et al., 2003; Vance and Hayashi, 2010). Accordingly, studies performed in humans suggest that apoE4 is significantly less lipidated than apoE3 (Hanson et al., 2013). Corresponding studies with transgenic mice expressing human apoE show that less apoE4 is associated with lipoproteins compared with apoE3 (Youmans et al., 2012; Tai et al., 2013). Furthermore, apoE4 is markedly less potent than apoE3 in promoting the efflux of cholesterol and phos-

\footnotetext{
Received Dec. 12, 2013; revised April 2, 2014; accepted April 3, 2014.

Author contributions: A.B.-C. and D.M.M. designed research; A.B.-C. performed research; A.B.-C. analyzed data; A.B.-C. and D.M.M. wrote the paper.

The research leading to these results received funding from the EU FP7 (Project Grant Agreement No. 211696), the Joseph K. and Inez Eichenbaum Foundation, the Diane Pregerson Glazer and Guilford Glazer Foundation, and from Harold and Eleanore Foonberg. We thank Alex Smolar for technical assistance and for maintaining the mouse colonies.

The authors declare no competing financial interests.

Correspondence should be addressed to Daniel M. Michaelson, Department of Neurobiology, The George S. Wise Faculty of Life Sciences, Tel Aviv University, Ramat Aviv 69978, Tel Aviv, Israel. E-mail: dmichael@post.tau.ac.il.

DOI:10.1523/JNEUROSCI.5198-13.2014

Copyright $\odot 2014$ the authors $\quad 0270-6474 / 14 / 347293-09 \$ 15.00 / 0$
}

pholipids from both astrocytes and neurons in culture (Michikawa et al., 2000; Riddell et al., 2008; Minagawa et al., 2009).

The ATP-binding cassette transporters A1 and G1 (ABCA1 and ABCG1, respectively) are important apoE-lipidating proteins (Hirsch-Reinshagen et al., 2004; Wahrle et al., 2004). ABCA1 preferentially stimulates the efflux of cholesterol and its binding to lipid-free acceptors, such as lipid-free apoE, whereas ABCG1 is more selective for partially lipidated lipoprotein complexes (Karten et al., 2006; Kim et al., 2008). The retinoid X receptor (RXR) system regulates the expression of ABCA1 and ABCG1, as well as that of apoE, by forming heterodimers with the liver X receptor (LXR), which then binds to distinct promoter sequences, thereby activating gene expression (Chawla et al., 2001; Laffitte et al., 2001; Liang et al., 2004). It has been shown recently that treatment of APP/PS1-transgenic mice with the RXR agonist bexarotene stimulates the synthesis of mouse $A B C A 1, A B C G 1$, and apoE and that this leads to the clearance of brain $A \beta$ and reversal of cognitive deficits (Cramer et al., 2012).

Application of such an approach to mice that express human apoE4 could potentially be double edged. Bexarotene induces an increase in ABCA1 and ABCG1 levels, which is expected to increase the lipidation of apoE4 and thus to have a beneficial effect, compensating for the decreased lipidation of native apoE4. However, because some of the pathological effects of apoE4 are associated with a gain of toxic function (Levi and Michaelson, 2007; Zepa et al., 2011), it is also possible that activation of the RXR 
system will have detrimental effects due to an increase in the levels of the apoE4 protein.

In the present study, we investigated the effects of bexarotene treatment on the levels of apoE, ABCA1, and ABCG1 in young, naive apoE3- and apoE4-targeted replacement (TR) mice and assessed the extent to which this is associated with reversal or exacerbation of the apoE4-driven pathological phenotype. This includes lipidation and synaptic impairments, as well as accumulation of $\mathrm{A} \beta 42$ and hyperphosphorylated tau in hippocampal neurons of young apoE4 mice and their behavioral impairments (Liraz et al., 2013; Salomon-Zimri et al., 2014).

\section{Materials and Methods \\ Mice}

ApoE-TR mice, in which the endogenous mouse apoE was replaced by either human apoE3 or apoE4, were created by gene targeting as described previously (Sullivan et al., 1997). The mice used were purchased from Taconic. Mice were back-crossed to wild-type C57BL/6J mice (2BL/ 610; Harlan Laboratories) for 10 generations and were homozygous for the apoE3 (3/3) or apoE4 (4/4) alleles. These mice are referred to herein as apoE3 and apoE4 mice, respectively. The apoE genotype of the mice was confirmed by PCR analysis, as described previously (Levi et al., 2003; Belinson and Michaelson, 2009). All experiments were performed on age-matched male animals (4 months of age) and were approved by the Tel Aviv University Animal Care Committee. Every effort was made to reduce animal stress and to minimize animal usage. The source of bexarotene used was the commercial formulation Targretin from Eisai (100 $\mathrm{mg} / \mathrm{kg}$, which translates to $2.5 \mathrm{mg}$ dissolved in $200 \mu \mathrm{l}$ of double distilled water (DDW) per mouse weighing $25 \mathrm{~g}$ ), which has better solubility and tissue accessibility than bexarotene powder. Bexarotene or DDW (control) were administered to 4-month-old apoE3 and apoE4 mice by oral gavage daily for $10 \mathrm{~d}$. After treatment, the mice were anesthetized with ketamine and xylazine and perfused transcardially with PBS. Their brains were then removed and halved and each hemisphere was further processed for either biochemical or histological analysis, as outlined in the succeeding paragraph. Each of the four groups (apoE3 or apoE4 $\times$ control or bexarotene) consisted of five to seven mice and the experiment was performed on two different cohorts of mice.

\section{Immunohistochemistry and immunofluorescence confocal microscopy}

One brain hemisphere was fixed overnight with $4 \%$ paraformaldehyde in $0.1 \mathrm{~m}$ phosphate buffer, $\mathrm{pH} 7.4$, and then placed in $30 \%$ sucrose for $48 \mathrm{~h}$. Frozen coronal sections ( $30 \mu \mathrm{m})$ were then cut on a sliding microtome, collected serially, placed in $200 \mu \mathrm{l}$ of cryoprotectant (containing glycerin, ethylene glycol, and $0.1 \mathrm{~m}$ sodium-phosphate buffer, $\mathrm{pH}$ 7.4), and stored at $-20^{\circ} \mathrm{C}$ until use. The free-floating sections were immunostained with the following primary antibodies (Abs): rabbit anti-A $\beta 42$ (1:500; Millipore); mouse anti-202/205 phosphorylated tau (AT8, 1:200; Innogenetics); mouse anti-212/214 phosphorylated tau (AT100, 1:500; Innogenetics); mouse antiThr181 phosphorylated tau (AT270, 1:500; Innogenetics); guinea pig antivesicular glutamatergic transporter 1 (VGluT1, 1:2000; Millipore).

Immunohistochemistry was performed as described previously (Belinson et al., 2008). Sections were washed with $10 \mathrm{~mm}$ PBS, pH 7.4, and blocked for $1 \mathrm{~h}$ in $20 \%$ serum diluted in PBS with $0.1 \%$ Triton X-100 (PBST), after which the primary Ab, diluted in PBST containing $2 \%$ of the appropriate serum, was applied overnight at $4^{\circ} \mathrm{C}$. The sections were then rinsed in PBST and incubated for $1 \mathrm{~h}$ at room temperature with the corresponding secondary $\mathrm{Ab}$ (Vector Laboratories) diluted 1:1000 in PBST containing $2 \%$ of the appropriate serum. After several additional rinses in PBST, the sections were incubated for $0.5 \mathrm{~h}$ in avidin-biotinhorseradish peroxidase complex (ABC Elite; Vector Laboratories) in PBST. After rinses in PBST, sections were placed for up to $10 \mathrm{~min}$ in diaminobenzidine chromagen solution (Vector Laboratories). To minimize variability, sections from all animals of the same cohort were stained simultaneously. The reaction was monitored visually and stopped by rinses in PBS. The sections were mounted on a dry-gelatincoated slide and then dehydrated and sealed with coverslips. $A \beta$ staining was performed similarly except that the sections were preincubated with $70 \%$ formic acid for 7 min to increase antigen retrieval before staining. The immunostained sections were viewed using a Zeiss Axioskop light microscope interfaced with a Kodak Megaplus CCD video camera. Photographs of stained brains were obtained at $10 \times$ magnification. Analysis and quantification of the staining ( 2 hippocampal sections per animal at bregma -1.7 to -2.06 ) were performed using the Image-Pro plus system for image analysis (version 5.1; Media Cybernetics). The images were analyzed by marking the area of interest (e.g., a hippocampal CA3 subfield) and setting a threshold for all sections subjected to the same staining. The stained area above the threshold relative to the total area was then determined for each section. All of the groups were stained together and the results presented correspond to the mean \pm SEM of the percent area stained normalized relative to the young control apoE3 mice.

Immunofluorescence staining was performed using fluorescent chromogens. Accordingly, sections were first blocked (incubation with $20 \%$ normal goat serum in PBST for $1 \mathrm{~h}$ at room temperature) and then reacted for $48 \mathrm{~h}$ at $4^{\circ} \mathrm{C}$ with the primary Abs (dissolved in $2 \%$ normal goat serum in PBST). Next, the bound primary Abs were visualized by incubating the sections for $1 \mathrm{~h}$ at room temperature with Alexa Fluor 488conjugated goat anti-guinea pig (1:1000; Invitrogen). The sections were then mounted on dry-gelatin-coated slides. Sections stained for immunofluorescence were visualized using a confocal scanning laser microscope (LSM 510; Zeiss). Images $(1024 \times 1024$ pixels, 12 bit $)$ were acquired by averaging eight scans. Control experiments revealed no staining in sections lacking the first $\mathrm{Ab}$. The intensities of immunofluorescence staining were calculated using the Image-Pro Plus system (version 5.1; Media Cybernetics) as described previously (Belinson et al., 2008). All images for each immunostaining were obtained under identical conditions and their quantitative analyses were performed with no further handling. Moderate adjustments for contrast and brightness were performed similarly on all the presented images of the different mouse groups. The images were analyzed by setting a threshold for all sections of a specific labeling. The area of staining over the threshold relative to the total area of interest was determined and averaged for each mouse and each group.

\section{A $\beta 42$ ELISA measurements}

The levels of mouse $\mathrm{A} \beta \mathrm{X}-42$ ( $\mathrm{A} \beta 42)$ were determined using the Beta Amyloid X-42 ELISA kit from Covance (catalog \#SIG-38952). Whole hippocampi were homogenized in $180 \mu \mathrm{l}$ of Tris-buffered saline (TBS; 20 mu Tris, $\mathrm{pH} 7.4$, containing $150 \mathrm{~mm} \mathrm{NaCl}$ ) with protease inhibitor (Roche). Triton X-100 was then added to a final concentration of $1 \%$ (TBSX) and the samples were agitated by pipetting up and down. The homogenates were than ultracentrifuged $(350,000 \times g$ for $20 \mathrm{~min})$ and the supernatant subjected to ELISA according to the manufacturer's specifications.

\section{Immunoblot analysis}

Immunoblot analysis was performed as described previously (Haas et al., 2012; Kariv-Inbal et al., 2012). In brief, the hippocampus was rapidly removed from one freshly excised hemisphere and stored frozen at $-70^{\circ} \mathrm{C}$ until use. The dissected hippocampus was then homogenized in $200 \mu \mathrm{l}$ of the following buffer: $10 \mathrm{~mm}$ HEPES, pH 7, containing $2 \mathrm{~mm}$ EDTA, 2 mm EGTA, 0.5 mm DTT, protease inhibitor mixture (P8340; Sigma), and phosphatase inhibitor mixture (P5726; Sigma). The homogenates were then aliquoted and stored at $-70^{\circ} \mathrm{C}$. For SDSelectrophoresis, the samples were boiled for $10 \mathrm{~min}$ with $0.5 \%$ SDS and immunoblotted as described previously (Belinson et al., 2008; Haas et al., 2012). The following Abs were used: mouse anti-VGluT1 (1:1000; Millipore); goat anti-apoE (1:10,000, Millipore); rabbit anti-ABCA1 (1:500; Novus); rabbit anti-ABCG1 (1:2000; Novus); and mouse anti-GAPDH (1:1000; Abcam). Protein concentration was determined using the BCA protein assay kit (23225; Pierce). The immunoblot bands were visualized using the ECL chemiluminescent substrate (Pierce), after which their intensity was quantified using EZQuantGel software (EZQuant). GAPDH levels were used as gel-loading controls and the results are presented relative to the control apoE3 mice. 


\section{Nondenaturing (native) immunoblot analysis}

Freshly excised hippocampai from control and bexarotene-treated apoE4 mice and their corresponding apoE3 mice were gently pressed through a $40 \mu \mathrm{m}$ cell strainer using a plunger from a $1 \mathrm{ml}$ syringe (Evans et al., 2014). The extract was briefly centrifuged to dispose of crude debris and then run on a nondenaturing 3-16\% gradient gel. The gels were then transferred to a nitrocellulose membrane and stained with goat antiapoE Ab (1:10000; Millipore). The immunoblot bands were visualized using the ECL chemiluminescent substrate (Pierce). Analysis of the apoE content in the tissue extract and the remaining tissue by SDS gel revealed that $>80 \%$ of the total apoE was extracted by this procedure.

\section{qRT-PCR analysis}

qRT-PCR analysis was performed as described previously (Gilat-Frenkel et al., 2013). In brief, the hippocampus was rapidly excised from one freshly removed hemisphere and stored frozen at $-70^{\circ} \mathrm{C}$ until use. RNA was extracted from the tissue using the MasterPure RNA purification kit (Epicenter). RNA was transformed into cDNA using the High Capacity cDNA reverse transcription kit (Applied Biosystems). TaqMan qRTPCR assays were conducted according to the manufacturer's specifications (Applied Biosystems). Oligonucleotides ( probes) for TaqMan qRT PCR were attached to FAM (6-carboxyfluorescin) at the $5^{\prime}$ end and a quencher dye at the $3^{\prime}$ end. ApoE, ABCA1, and ABCG1 gene expression levels were determined using TaqMan qRT-PCR specific primers (Applied Biosystems). Analysis and quantification were conducted using the 7300 system software and compared with the expression of the housekeeping HPRT-1 gene.

\section{Behavioral testing}

The behavioral tests were initiated $10 \mathrm{~d}$ after the beginning of the bexarotene treatment. The mice were first subjected to the novel object recognition test for $3 \mathrm{~d}$ and then, after a $2 \mathrm{~d}$ interval, to the Morris water maze for $4 \mathrm{~d}$. The mice were administered either DDW or bexarotene daily throughout this testing period.

Novel object recognition test. This was performed as described previously (Salomon-Zimri et al., 2014). In brief, the mice were first placed in an arena $(60 \times 60 \mathrm{~cm}$ with $50 \mathrm{~cm}$ walls $)$ in the absence of objects, after which two identical objects were added. Either $2 \mathrm{~h}$ (short-term memory test) or $24 \mathrm{~h}$ (long-term memory test) later, the mice were reintroduced to the arena in which one of the objects was replaced by a novel one. The behavior of the mice was then monitored using the EthoVision XT 9 program for $5 \mathrm{~min}$, and the time and number of visits that the mice paid to each of the objects were measured. The results are presented as the ratio in percentage of the time spent near the novel object relative to the total time spent near both new and old objects.

Morris water maze. The Morris water maze test was performed as described previously (Salomon-Zimri et al., 2014). Mice were placed in a $140 \mathrm{~cm}$ circular pool with the water rendered opaque with milk powder. A $10 \mathrm{~cm}$ circular platform submerged $1 \mathrm{~cm}$ below the surface of the water was placed at a fixed position. The mice were subjected to 4 trials per day for $4 \mathrm{~d}$ such that, for each trial, the mice were placed in 1 of equally spaced locations along the perimeter of the pool. The intertrial interval was 30 min and the location of the platform was unchanged between days. The mice were introduced to the arena from four random locations, the order of which was unchanged between days. The performance of the mice was monitored by measuring the time they took to reach the platform. A probe test was performed after the last trial of the fourth day, in which the hidden platform was removed from the arena and the amount of time the mice spent in the quadrant in which the platform was located and in the other quadrants was measured. Measurements were performed using the computerized video-assisted HVS water maze system (HVS Image).

\section{Statistical analysis}

The experimental design consisted of two genotypes (apoE3 and apoE4) and two treatments (control and bexarotene) and the results were analyzed using two-way ANOVA testing with STATISTICA software (version 8.0; StatSoft). Further post hoc Tukey analysis was performed to test for individual effects. Each of the four groups contained five to seven mice and the experiments were performed on two different cohorts of mice. The histological, biochemical, and behavioral results obtained with the two cohorts were similar and they are presented jointly after normalization of each of the experiments relative to the apoE3 control group. Similar results were obtained when the two cohorts were analyzed separately.

\section{Results \\ Effect of bexarotene on the levels of ABCA1, ABCG1, and apoE}

The effects of the RXR-agonist bexarotene on the expression levels of ABCA1, ABCG1, and apoE are depicted in Figure 1. As can be seen, the mRNA levels of ABCA1 and ABCG1 were both similar in control apoE3 and apoE4 mice and were similarly increased in these mice after bexarotene treatment $(p=0.0001$ and $p=0.001$ by 2 -way ANOVA for the effect of treatment on the mRNA levels of ABCA1 and ABCG1, respectively). In contrast, the apoE mRNA levels, which were similar in the control apoE3 and apoE4 mice, were not affected by bexarotene treatment (Fig. $1 A$ ). Measurements of the corresponding protein levels revealed that the levels of ABCA1 were similar in the apoE3 and apoE4 control mice and were similarly increased by bexarotene $(p=$ 0.0001 by 2 -way ANOVA for the effect of treatment). Measurements of the ABCG1 protein levels also revealed a significant effect of treatment ( $p=0.0001$ by 2 -way ANOVA), which was accompanied by a small yet significant effect of apoE genotype ( $p=0.002$ by 2 -way ANOVA). Consistent with previous results (Liraz et al., 2013), measurements of apoE protein levels revealed that the apoE4 control mice had lower levels of apoE than the corresponding apoE3 mice ( $p=0.0001$ by 2 -way ANOVA for the effect of genotype). Bexarotene had no significant effect on the apoE levels of either mouse group (Fig. 1B). The finding that apoE4 mice have lower levels of apoE compared with the apoE3 mice, but that they have similar mRNA levels, suggests that the lower apoE levels in apoE4 mice are due to a posttranslational effect such as increased degradation.

The extent to which the increase in ABCA1 and ABCG1 levels by bexarotene is associated with increased lipidation of apoE was investigated using native gel electrophoresis. As can be seen in Figure 2, apoE positive reactivity in the native gel is significantly lower in the control apoE4 mice than in the control apoE3 mice. Importantly, the decreased levels of native apoE4 mice compared with native apoE3 mice is markedly more pronounced than the corresponding decrease in total apoE levels between these mouse groups (cf. Figs. 2, 1B), suggesting that, in the control mice, apoE4 is indeed less lipidated than apoE3. Interestingly, control apoE3 homogenates contain a broader spectrum of apoE species than the apoE4 homogenates. Bexarotene treatment had a marked effect on the lipidation of apoE. Accordingly, in the apoE4 mice, bexarotene increased the level of high-molecularweight apoE species, whereas in the apoE3 mice, this was associated with an increase in the high-molecular-weight species and a concurrent decrease in the low-molecular-weight species. Together, these results suggest that the bexarotene-induced increase in the levels of ABCA1 and ABCG1 results in increased lipidation of apoE.

\section{Reversal of apoE4-driven brain pathology by bexarotene}

The extent to which bexarotene can reverse the pathological phenotype of apoE4 in TR mice was first assessed by focusing on the apoE4-driven accumulation of $\mathrm{A} \beta 42$ and hyperphosphorylated tau in CA3 neurons, which is the hippocampal subfield in which these pathologies were most pronounced (Liraz et al., 2013). As can be seen in Figure $3 A$, and consistent with previous results 
A

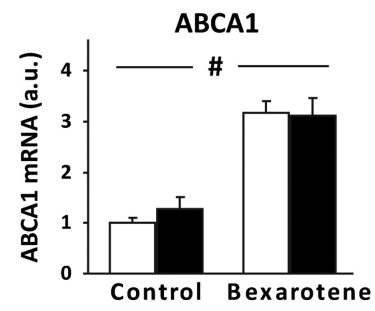

B
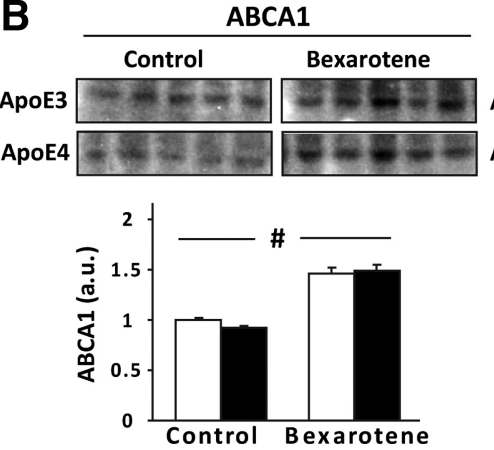

ABCG1

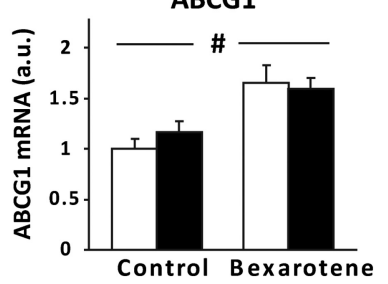

ABCG1
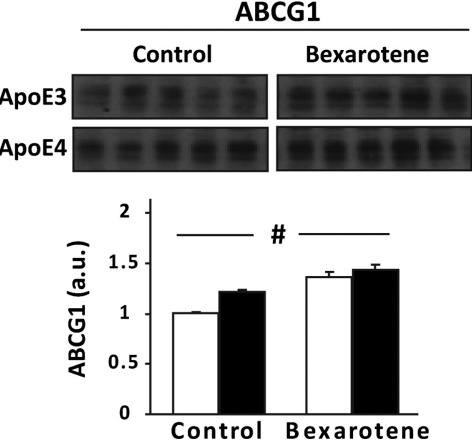

ApoE

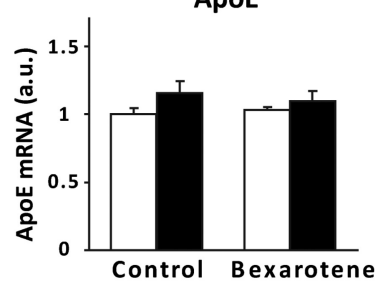

ApoE
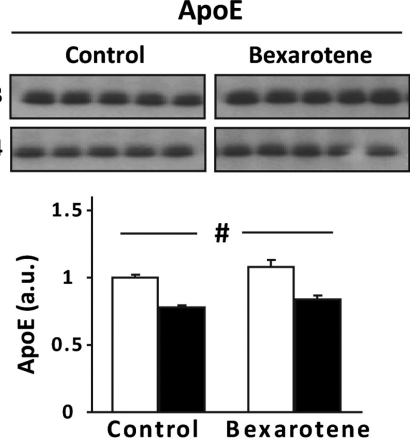

Figure 1. The effect of bexarotene on the mRNA and protein levels of apoE, $A B C A 1$, and $A B C G 1$ in hippocampal neurons of apoE3 and apoE4 mice. $A$, qRT-PCR measurements of the mRNA levels of $A B C A 1, A B C G 1$, and apoE mice. The experiments were performed as described in Materials and Methods and the results are normalized relative to control apoE3 mice $($ mean \pm SEM; $n=5$ per group). White bars correspond to apoE3 mice, whereas black bars correspond to apoE4 mice. $\boldsymbol{B}$, Immunoblot assays of the corresponding protein levels of $A B C A 1, A B C G 1$, and apoE mice. Whole hippocampi from control and bexarotene apoE3 and apoE4 mice were subjected to immunoblot assays using anti-apoE, anti-ABCG1, and anti-ABCA1 Abs as described in Materials and Methods. The results are normalized relative to control apoE3 mice (mean $\pm \mathrm{SEM} ; n=10$ per group). $\# p=0.0001$ by 2 -way ANOVA for the effect of treatment on $\mathrm{ABCA} 1$ and $\mathrm{ABCG} 1$ protein levels and on $\mathrm{ABCA} 1$ mRNA levels and $\# p=0.001$ for the effect of treatment on the $A B C G 1$ mRNA levels $(F=148.4, F=48.06$ for $A B C A 1$ and $A B C G 1$ protein levels and $F=17.82$ and $F=17.02$ for $A B C A 1$ and $A B C G 1$ mRNA levels, respectively). $\# p=0.0001(F=45.79)$ for the effect of genotype on apoE protein levels by 2-way ANOVA.

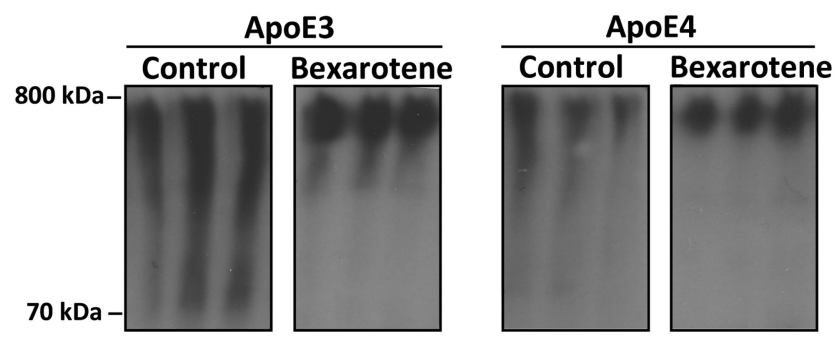

Figure 2. The effect of bexarotene on apoE lipidation in the hippocampus of apoE3 and apoE4 mice. Freshly excised hippocampi from control and bexarotene-treated apoE4 and apoE3 mice were subjected to a nondenaturing $3-16 \%$ gradient gel and blotted using anti-apoEAb, as described in Materials and Methods. As can be seen, the levels of apoE reactivity are lower in the control apoE4 mice compared with the control apoE3 mice and bexarotene treatment causes a significant increase in the appearance of high-molecular-weight species of apoE in both apoE4 and apoE3 mice.

(Liraz et al., 2013), the levels of immunohistochemically determined $\mathrm{A} \beta 42$ were higher in the control apoE4 mice than in the control apoE3 mice. Bexarotene treatment markedly reduced the levels of $A \beta 42$ in both the apoE3- and the apoE4-treated mice ( $p=0.0001$ by 2 -way ANOVA for the effect of treatment). This effect was more substantial in the apoE4 mice and virtually abolished the difference in the $\mathrm{A} \beta 42$ levels between the apoE4 and apoE3 mice. Similar results were obtained using an ELISA kit for $\mathrm{A} \beta 42$ and whole hippocampal homogenates. As shown in Figure $3 B$, this revealed that the levels of $A \beta 42$ were higher in the control apoE4 mice compared with the control apoE3 mice and that this effect was counteracted by treatment with bexarotene $(p=0.012$ by 2 -way ANOVA for the effect of treatment $\times$ genotype). Further post hoc analysis revealed that the levels of $\mathrm{A} \beta 42$ were significantly higher in the apoE4 control mice compared with the corresponding apoE3 mice $(p=0.04)$ and that the bexaroteneinduced decrease in $\mathrm{A} \beta 42$ levels was also significant $(p=0.024)$.
The ELISA results, which were obtained using TBSX-extracted $\mathrm{A} \beta 42$, correspond to measurements of intracellular and extracellular $A \beta 42$, whereas the immunohistochemical staining mainly detects intracellular $A \beta 42$. Accordingly, because both techniques yielded a similar apoE4-driven effect, this suggests that the apoE4-driven effects on $A \beta 42$ are primarily intracellular. Together, these results suggest that bexarotene counteracts the apoE4-induced accumulation of $A \beta 42$. This effect seems to be specific to $A \beta 42$, because the histochemically measured levels $\mathrm{A} \beta 40$ are not affected by either genotype or treatment (data not shown).

The effects of apoE genotype and bexarotene treatment on tau hyperphosphorylation in CA3 hippocampal neurons are shown in Figure 4. As can be seen and consistent with previous findings (Liraz et al., 2013), the levels of tau phosphorylation using the AT8 mAb were higher in the control apoE4 mice than in the corresponding apoE3 mice. Bexarotene treatment induced a marked decrease in the levels of AT8 tau phosphorylation in apoE4-treated mice, but not in the apoE3-treated mice $(p=$ 0.0002 for the effect of treatment and $p=0.00035$ for the effect of genotype $\times$ treatment by 2 -way ANOVA). Post hoc analysis revealed that the levels of tau phosphorylation were indeed higher in the apoE4 control mice compared with the corresponding apoE3 mice $(p=0.005)$ and that the bexarotene-induced decrease in tau phosphorylation in the apoE4 mice was also significant $(p=0.0002)$. In contrast to the results obtained with the AT8 mAb, the extent of phosphorylation of tau at the sites recognized by AT $100 \mathrm{mAb}$ was not affected by either apoE genotype or treatment (Fig. 4B). Similar results were obtained using the antiphosphorylated tau mAb AT270 (data not shown).

The effects of bexarotene on the levels of the synaptic marker VGluT1 are depicted in Figure 5. As can be seen, and consistent with previous findings (Liraz et al., 2013), the levels of VGluT1 in 
A

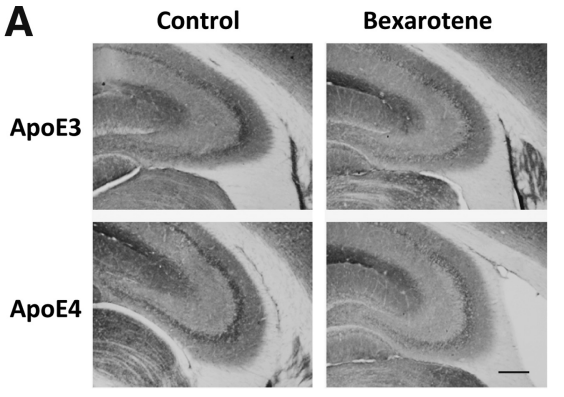

B

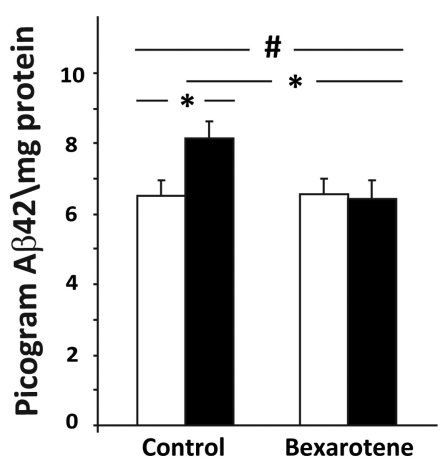

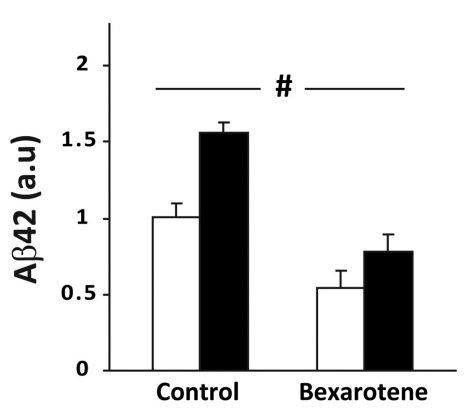

$55 \pm 9 \%$ for bexarotene-treated apoE4 mice in the CA1 the DG). For the VGluT1, the levels of staining were lower for the control apoE4 mice compared with the corresponding apoE3 mice in both the CA1 and DG $(87 \pm 12 \%$ and $79 \pm 3 \%$, respectively) and were elevated by bexarotene in both subfields $(95 \pm 12 \%$ in the CA1 and $106 \pm 2 \%$ in the DG).

\section{Reversal of apoE4-driven behavioral deficits by bexarotene}

The extent to which the reversal of the apoE4-induced brain pathological effects by bexarotene is associated with improvement of the cognitive performance of the apoE4 mice was examined next. Results obtained in the Morris water maze are depicted in Figure 6. As can be seen, all mouse groups performed similarly on the first day of the experiment. However, whereas the control apoE3 mice improved their performance in the swim test and reached a plateau by the second day of the test, the control apoE4 mice were impaired in their performance and took longer to reach the plateau. This apoE4-induced deficit was reversed by bexarotene treatment, which had no effect on the apoE3 mice's performance $(p=0.047$ for the effect of genotype $\times$ treatment by repeatedmeasures ANOVA analysis and $p=$ 0.0006 for the corresponding Tukey post hoc comparison of the control and bexarotene-treated apoE4 mice). After the last trial on the fourth day of the Morris water maze, the mice were subjected to a probe test in which the hidden platform

the apoE4 control mice were lower than those observed in the corresponding apoE3 mice. Treatment with bexarotene increased the levels of VGluT1 in the apoE4 mice. Bexarotene had no effect on the apoE3-treated mice, thus rendering the levels of VGluT1 similar in the treated apoE3- and apoE4 mice $(p=0.001$ for the effect of genotype $\times$ treatment by 2 -way ANOVA). Further post hoc analysis revealed that the reduced levels of VGluT1 in the apoE4 mice was significant relative to control apoE3 mice $(p=0.0002)$, as was the effect of bexarotene treatment on the apoE4 mice $(p=0.0003)$. Similar results were obtained by Western blot analysis of VGluT1 levels of the corresponding mouse groups (data not shown).

Bexarotene also counteracted the effect of apoE4 on the levels of $\mathrm{A} \beta 42$, hyperphosphorylated tau, and VGluT1 in the CA1 and DG hippocampal subfields. These effects, however, were less pronounced than those observed in the CA3 (Liraz et al., 2013). Specifically, the levels of $\mathrm{A} \beta 42$, which were higher in control apoE4 compared with the control apoE3 in the CA1 ( $135 \pm 2 \%$ of control apoE3 mice) and similar in the DG subfields (101 $\pm 2 \%$ of control apoE3 mice), were both decreased in the apoE4 mice after bexarotene treatment ( $92 \pm 13 \%$ of control apoE3 and $79 \pm$ $7 \%$ of control apoE3 in the CA1 and DG, respectively). Similar results were obtained with AT8 tau-phosphorylation levels $(115 \pm 7 \%$ and $116 \pm 17 \%$ for control apoE4 mice relative to control apoE3 in the CA1 and DG, respectively, and $82 \pm 9 \%$ and was removed from the arena and the mice's preferences for the different quadrants of the arena were assessed. This test revealed that the control apoE3 mice spent more time in the quadrant where the platform was originally located than in the other quadrants, whereas the apoE4 mice showed no preference to any of the quadrants (Fig. 6B). Treatment with bexarotene resulted in an increase in the time that the apoE4 mice spent in the relevant quadrant and rendered their performance equal to that of the apoE3 mice, the performance of which was not affected by bexarotene. These effects were associated with a significant effect of treatment ( $p=0.028$ by 2 -way ANOVA).

The mice were next subjected to the novel object recognition test in which their tendency to approach a novel object was measured. Mice were exposed to new and old objects $2 \mathrm{~h}$ (short-time interval) and $24 \mathrm{~h}$ (long-time interval) after the initial exposure to 2 similar objects. The results are depicted in Figure 7. As can be seen, at both time points, the control apoE3 mice spent more time near the new object, whereas the control apoE4 mice showed no such preference and visited the new and old object similarly. This difference between the control apoE3 and apoE4 mice was abolished by bexarotene at both time points, such that, under these conditions, both mouse groups approached the new object preferentially. Statistical analysis revealed a significant effect of genotype $\times$ treatment at the $24 \mathrm{~h}$ time point ( $p=0.034$ by 2 -way ANOVA analysis). 
Further post hoc analysis revealed that the decreased preference of the control apoE4 mice to the new object relative to that of the control apoE3 mice was indeed significant $(p=0.0014)$, as was the effect of bexarotene treatment on the apoE4 mice $(p=0.001)$. A similar trend, though not statistically significant, was obtained at the $2 \mathrm{~h}$ time point. Control experiments revealed that the mice had no preference to either corner of the arena and that there were no differences in the locomotor activity (velocity or distance traveled) between the groups when placed in an open field arena in the absence of an object.

\section{Discussion}

This study investigated the effect of bexarotene on the levels of apoE, ABCA1, and ABCG1 in hippocampal neurons of young apoE3 and apoE4-TR mice and the extent to which it could reverse the apoE4-driven brain pathology and cognitive impairments of the apoE4 mice. The results revealed that bexarotene increases the mRNA and protein levels of both ABCA1 and ABCG1, but does not affect either the mRNA or protein levels of apoE of either mouse group. These biochemical effects were associated with bexarotene-induced reversal of the lipidation deficits of the apoE4 mice and their cognitive impairments in the object recognition and Morris water maze. In addition, bexarotene treatment reversed the apoE4-driven accumulation of $\mathrm{A} \beta 42$ and hyperphosphorylated tau, as well as the decrease in the levels of the presynaptic marker VGluT1.

The present finding that bexarotene increases in the levels of ABCA1 and ABCG1 is consistent with previous results (Cramer et al., 2012; Tesseur et al., 2013; Veeraraghavalu et al., 2013). In contrast, bexarotene, which is known to increase the expression of mouse apoE (Price et al., 2013; Veeraraghavalu et al., 2013), does not affect the levels of human apoE in the TR mice. This is consistent with recent findings obtained with the same mouse groups by Drs. David Holtzman and Jason Ulrich (personal communication) and with corresponding cell cultures by Dr. Gary Landerth (personal communication). Interestingly, studies with a different LXR agonist, T0901317, revealed that the expression of apoE is upregulated in human astrocytoma cells by T0901317 (Liang et al., 2004), but that it has little to no effect on cells and brains of mouse origin (Whitney et al., 2002; Liang et al., 2004; Koldamova et al., 2005). The regulatory regions in the mouse apoE gene and the human apoE gene in the TR mice are the same, so these findings or treatment. analysis.
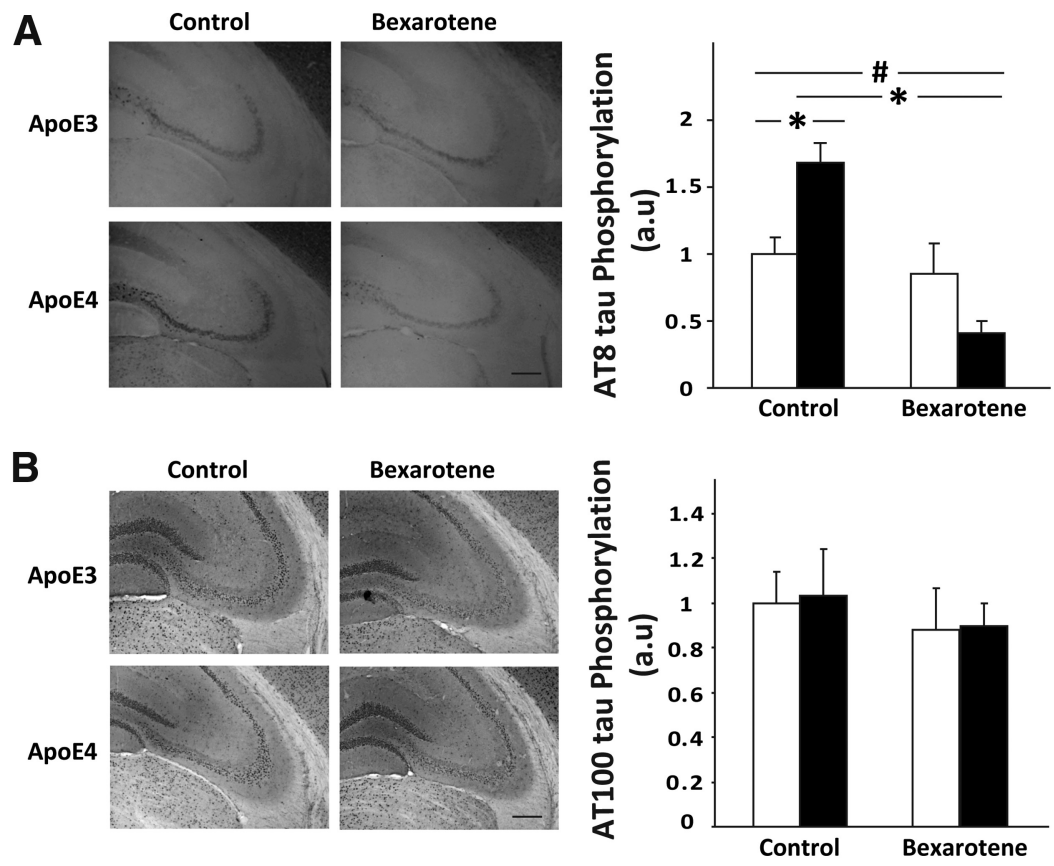

Figure 4. The effect of bexarotene on the levels of hyperphosphorylated tau in CA3 neurons of apoE3 and apoE4 mice. $\boldsymbol{A}$, Effect of bexarotene on AT8 tau phosphorylation. Brains of control and bexarotene-treated apoE4 and apoE3 mice were sectioned and subjected to histological staining using AT8, a marker for tau phosphorylation (Ser202/Thr205). Representative images (10X magnification) of the CA3 hippocampal subfield are presented on the left (scale bar, $200 \mu \mathrm{m}$ ) and show that the increased level of tau phosphorylation in the apoE4 mice compared with the apoE3 mice is abolished by bexarotene. Quantification of the results (mean \pm SEM; $n=12-14$ per group) of apoE3 mice (white bars) and apoE4 mice (black bars) was performed by computerized image analysis, as described in Materials and Methods, and is shown on the right. The results are normalized to control apoE3 mice. $\# p<0.001(F=23.2$ and $F=15)$ for the effect of treatment and of genotype $\times$ treatment by 2 -way ANOVA; ${ }^{*} p<0.001$ for the post hoc comparison of control apoE3 and apoE4 and for the effect of bexarotene on apoE4 mice by Tukey post hoc analysis. $\boldsymbol{B}$, Effect of bexarotene on AT100 tau phosphorylation. Experiments were performed and are depicted as described above. As can be seen, the results show no effect for genotype
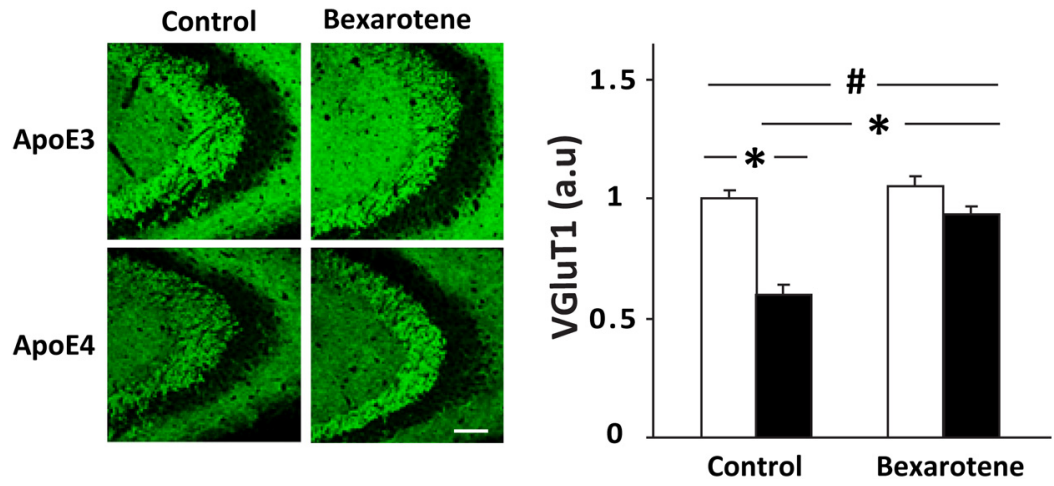

Figure 5. Effect of bexarotene on the levels of the glutamate vesicular transporter VGluT1 in CA3 neurons of apoE3 and apoE4 mice. Brains of control and bexarotene-treated apoE4 mice and their corresponding apoE3 mice were sectioned and subjected to histological staining using anti-VGluT1 Ab. Representative images ( $20 \times$ magnification) of the CA3 hippocampal subfield are presented on the left (scale bar, $80 \mu \mathrm{m}$ ) and show that the decreased levels in the control apoE4 mice relative to the apoE3 mice are increased by bexarotene. Quantification of the results (mean \pm SEM: $n=12-14$ per group) of apoE3 mice (white bars) and apoE4 mice (black bars) was performed by computerized image analysis, as described in Materials and Methods, and is shown on the right. Results are normalized to control apoE3 mice. \#p $<0.001(F=41.65$, $F=22.58$ and $F=12.4$ ) for the effect of genotype, treatment and genotype $\times$ treatment by 2 -way ANOVA; ${ }^{*} p<0.001$ for the post hoc comparison of control apoE3 and apoE4 and for the effect of bexarotene on apoE4 mice by Tukey post hoc

suggest the possibility that apoE gene sequences in the coding region that are specific to human apoE interacted differentially with the RXR-LXR system, thereby diminishing the effects of bexarotene. Although the nature of this effect is not yet known, it 
A

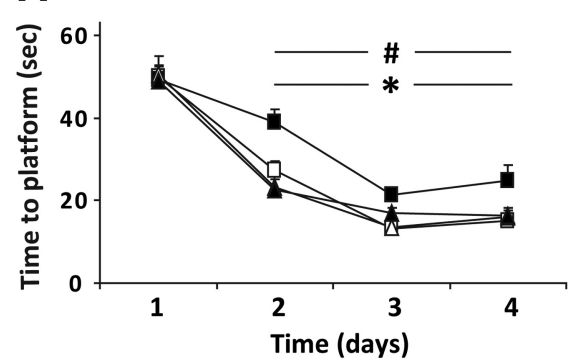

B

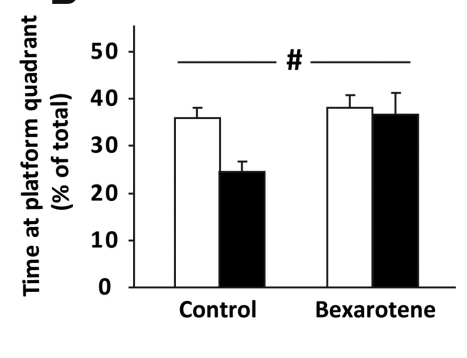

Figure 6. Effect of bexarotene on the performance of $\mathrm{apoE} 3$ and apoE4 mice in the Morris water maze. Control and bexarotene apoE4 mice and their corresponding apoE3 mice were subjected to a Morris water maze test. $\boldsymbol{A}$, Latency to reach the platform. Latency was tested across 4 daily trials for $4 \mathrm{~d}$, as described in Materials and Methods. The results shown are the average latencies of the 4 daily trials of each group in seconds ( $n=12-14$ per group). $\square$ and $\square$ correspond to control apoE3 and apoE4 mice, respectively. $\Delta$ and $\boldsymbol{\Delta}$ correspond to bexarotene-treated apoE3 and apoE4 mice, respectively. $\# p<0.05(F=2.86)$ for the effect of genotype $\times$ treatment by 2-way ANOVA; ${ }^{*} p<0.05$ for the effect of bexarotene on apoE4 mice by Tukey post hoc analysis. $\boldsymbol{B}$, Probe test. The hidden platform was removed from the arena and the time the mice spent in the quadrant in which the platform was located was measured, as described in Materials and Methods. The results are depicted as the percentage of time spent in the platform's quadrant out of the total trial time ( $n=6-7$ per group). White bars correspond to apoE3 mice, whereas black bars correspond to apoE4 mice. \#p $<0.05(F=5.47)$ for the effect of treatment by 2-way ANOVA.

A

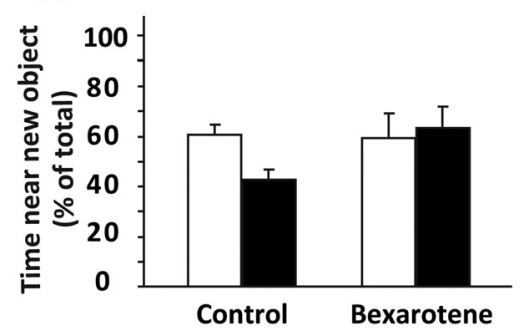

B

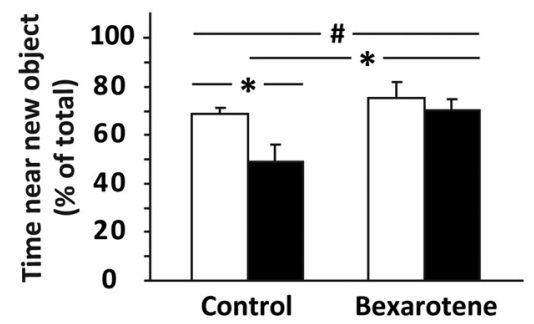

Figure 7. Effect of bexarotene on the performance of the apoE3 and apoE4 mice in the novel object recognition test. Control and bexarotene-treated apoE4 mice and corresponding apoE3 mice were first exposed to two identical objects (training session). This was followed by a delay of either 2 or $24 \mathrm{~h}$, after which the mice were exposed to an old and a new object. The preference of the mice to the different objects was monitored, as described in Materials and Methods. A, Short-term memory test performed $2 \mathrm{~h}$ after the training session. $\boldsymbol{B}$, Long-term memory test performed $24 \mathrm{~h}$ after the training session. The results obtained are presented as the percentage of time the mice spent near the novel object out of the total time spent near both old and novel objects. White bars correspond to apoE3 mice, whereas black bars correspond to apoE4 mice $(n=6-8$ per group).\#p $<0.05(F=5.13)$ for the effect of genotype $\times$ treatment by 2 -way ANOVA; ${ }^{*} p<0.05$ for the post hoc comparison of control apoE3 and apoE4 and for the effect of bexarotene on apoE4 mice by Tukey post hoc analysis.

has beneficial significance in terms of the ability to differentiate between effects of bexarotene related to lipidation and those related to modulation of the levels of apoE.

Our finding that bexarotene both increases the levels of $A B C A 1$ and $A B C G 1$ and the lipidation of apoE in both apoE3 and apoE4 hippocampal homogenates, as seen by native gels, is consistent with previous findings that bexarotene increases the levels of these proteins and the lipidation of mouse apoE in the brains of APP/PS1 mice (Cramer et al., 2012). Careful examination of the patterns of native apoE reveals that the apoE4 mice have lower levels of both the high- and the low-molecular-weight species of apoE compared with apoE3 (Fig. 2). Assuming that the lowmolecular-weight particles are precursors of the high-molecularweight species, this finding is consistent with apoE4-driven impairment in the initiation of the formation of the larger species. Nevertheless, the possibility that apoE4 enhances the degradation of the large and small apoE species cannot be ruled out. The mechanism by which the initial basal lipidation of apoE4 is lower than that of apoE3 may be related to differences in the interaction between apoE3 and apoE4 with the lipidation proteins and/or to the effect of apoE genotype on the compartmen- talization and accessibility of apoE3 and apoE4 to the lipidation proteins. The effect of bexarotene on apoE lipidation, which is most likely driven by the increased levels of ABCA1 and ABCG1, results in increased conversion of the lowmolecular-weight species to the highmolecular-weight species in the apoE3 mice. In contrast, in the apoE4 mice, the main effect is an increase in the highmolecular-weight species with no significant effect on the low-molecular-weight apoE particles. Further studies of the lipid and protein composition of the apoE species and the time course of their formation and degradation are required to unravel the effect of apoE genotype on apoE lipidation.

The present findings suggest that the sequence of events generated by the introduction of bexarotene is as follows: in naive mice, apoE4 is hypolipidated relative to apoE3. Bexarotene increases the mRNA levels of $A B C A 1$ and $A B C G 1$, thus leading to an increase in their protein level. ABCA1 and ABCG1 then mediate an increase in the lipidated species of apoE, in particular, a compensatory increase in the lipidation of apoE4. In the following paragraphs, we discuss the functional implications of these effects.

It was shown that, in astrocytic cultures from TR mice, the expression of apoE4 induces a deficiency in the transport of cholesterol relative to that observed in corresponding apoE3-secreting cells (Gong et al., 2002). Similar results were obtained in neuronal culture studies in which apoE was added exogenously, showing that apoE3 has a greater ability to induce cholesterol efflux than apoE4 (Michikawa et al., 2000; Minagawa et al., 2009). In view of the importance of cholesterol to membrane homeostasis and to the well-being of synapses, it is tempting to suggest that apoE4-indcued decrease in VGluT1 levels is also related to apoE4-driven specific impairments in lipidation of glutamatergic neurons, which, after bexarotene treatment, is reversed and returns to normal.

The effect of bexarotene on the levels of $A \beta 40$ and $A \beta 42$ was studied recently using different animal models and the same bexarotene preparation used in the present study. The majority of studies were performed on APP/PS1 transgenic mouse models and show a bexarotene-driven decrease in the levels of soluble $\mathrm{A} \beta 40$ or $\mathrm{A} \beta 42$ in the interstitial fluid (Cramer et al., 2012; Ulrich et al., 2013). A similar bexarotene-induced decrease in $A \beta$ levels was observed in other mouse models, such as APP/human apoE (Fitz et al., 2013) and 5XFAD mice (Veeraraghavalu et al., 2013), and in in vitro models (Bachmeier et al., 2013). Our present finding that bexarotene decreases the level of intracellular $\mathrm{A} \beta 42$ in the hippocampus of TR mice is consistent with these studies. In contrast to the consistency in the literature regarding the effect of bexarotene on the levels of $A \beta 40$ and $A \beta 42$, the observed effect of bexarotene on the size and number of $A \beta$ plaques in these studies 
remains controversial. Several mechanisms have been suggested regarding the cross interactions between apoE4 and the $\mathrm{A} \beta$ life cycle. These include decreased binding efficiency of apoE4 to A $\beta$ compared with apoE3, resulting in diminished apoE4 clearance of $\mathrm{A} \beta$ (Tokuda et al., 2000), increased $\mathrm{A} \beta$ production (Ye et al., 2005; He et al., 2007), and impaired A $\beta$-degrading efficiency (Jiang et al., 2008). The extent to which these different mechanisms mediate the apoE4-driven accumulation of $A \beta$ in hippocampal neurons and are susceptible to the diminished lipidation of apoE4, and thus to treatment with bexarotene, remains to be determined.

Previous in vitro and cell culture studies suggest that apoE4 or fragments of apoE4 may differentially affect tau hyperphosphorylation by direct interaction with either tau or other cytoskeletal components (Strittmatter et al., 1994; Chang et al., 2005). In addition, it has been shown that apoE4 can affect tau phosphorylation indirectly via signaling elements such as the Erk pathway (Harris et al., 2004) or glycogen synthase kinase-3 $\beta$ (CedazoMínguez et al., 2003). Further research is required to reveal the extent to which one of these possible mechanisms underlies the effects of apoE4 on tau hyperphosphorylation in TR mice and its reversal by bexarotene treatment.

It is important to note that bexarotene also has peripheral effects. Consistent with previous results (Lalloyer et al., 2009), measurements of the effects of bexarotene on serum triglycerides levels revealed that bexarotene increases the levels of triglycerides in the serum of both apoE4 and apoE3-TR mice by twofold (data not shown). Although this effect was not associated with significant body weight changes in any of the mouse groups, the possibility that peripheral mechanisms play a role in mediating the bexarotene effect in apoE4 mice cannot be excluded.

In conclusion, our present findings show that treatment of TR mice expressing human apoE4 with the RXR ligand bexarotene results in reversal of both the brain pathologies and cognitive impairments that are driven by apoE4 and that this is due to bexarotene induced compensation for the lipid deficiency of apoE4. These findings suggest that RXR activation and increased levels of ABCA1 and ABCG1 may pave the way for a novel therapeutic approach for the treatment of human apoE4 carriers to counteract the pathological effects of apoE4 leading to $\mathrm{AD}$.

\section{References}

Bachmeier C, Beaulieu-Abdelahad D, Crawford F, Mullan M, Paris D (2013) Stimulation of the retinoid $\mathrm{X}$ receptor facilitates beta-amyloid clearance across the blood-brain barrier. J Mol Neurosci 49:270-276. CrossRef Medline

Belinson H, Michaelson DM (2009) ApoE4-dependent Abeta-mediated neurodegeneration is associated with inflammatory activation in the hippocampus but not the septum. J Neural Transm 116:1427-1434. CrossRef Medline

Belinson H, Lev D, Masliah E, Michaelson DM (2008) Activation of the amyloid cascade in apolipoprotein $\mathrm{E} 4$ transgenic mice induces lysosomal activation and neurodegeneration resulting in marked cognitive deficits. J Neurosci 28:4690-4701. CrossRef Medline

Cedazo-Mínguez A, Popescu BO, Blanco-Millán JM, Akterin S, Pei JJ, Winblad B, Cowburn RF (2003) Apolipoprotein E and beta-amyloid (1-42) regulation of glycogen synthase kinase-3beta. J Neurochem 87:11521164. CrossRef Medline

Chang S, ran Ma T, Miranda RD, Balestra ME, Mahley RW, Huang Y (2005) Lipid- and receptor-binding regions of apolipoprotein E4 fragments act in concert to cause mitochondrial dysfunction and neurotoxicity. Proc Natl Acad Sci U S A 102:18694-18699. CrossRef Medline

Chawla A, Boisvert WA, Lee CH, Laffitte BA, Barak Y, Joseph SB, Liao D, Nagy L, Edwards PA, Curtiss LK, Evans RM, Tontonoz P (2001) A PPAR gamma-LXR-ABCAl pathway in macrophages is involved in cholesterol efflux and atherogenesis. Mol Cell 7:161-171. CrossRef Medline
Corder EH, Saunders AM, Strittmatter WJ, Schmechel DE, Gaskell PC, Small GW, Roses AD, Haines JL, Pericak-Vance MA (1993) Gene dose of apolipoprotein E type 4 allele and the risk of Alzheimer's disease in late onset families. Science 261:921-923. CrossRef Medline

Cramer PE, Cirrito JR, Wesson DW, Lee CY, Karlo JC, Zinn AE, Casali BT, Restivo JL, Goebel WD, James MJ, Brunden KR, Wilson DA, Landreth GE (2012) ApoE-directed therapeutics rapidly clear beta-amyloid and reverse deficits in AD mouse models. Science 335:1503-1506. CrossRef Medline

Evans TA, Barkauskas DS, Myers JT, Hare EG, You JQ, Ransohoff RM, Huang AY, Silver J (2014) High-resolution intravital imaging reveals that blood-derived macrophages but not resident microglia facilitate secondary axonal dieback in traumatic spinal cord injury. Exp Neurol 254:109120. CrossRef Medline

Fitz NF, Cronican AA, Lefterov I, Koldamova R (2013) Comment on "ApoE-directed therapeutics rapidly clear beta-amyloid and reverse deficits in AD mouse models". Science 340:924-c. CrossRef Medline

Gilat-Frenkel M, Boehm-Cagan A, Liraz O, Xian X, Herz J, Michaelson DM (2013) Involvement of the Apoer2 and Lrp1 receptors in mediating the pathological effects of ApoE4 in vivo. Curr Alzheimer Res. Advance online publication. doi:10.2174/1567205010666131119232444. CrossRef Medline

Gong JS, Kobayashi M, Hayashi H, Zou K, Sawamura N, Fujita SC, Yanagisawa K, Michikawa M (2002) Apolipoprotein E (ApoE) isoformdependent lipid release from astrocytes prepared from human ApoE3 and ApoE4 knock-in mice. J Biol Chem 277:29919-29926. CrossRef Medline

Haas A, Liraz O, Michaelson DM (2012) The effects of apolipoproteins E3 and $\mathrm{E} 4$ on the transforming growth factor-beta system in targeted replacement mice. Neurodegener Dis 10:41-45. CrossRef Medline

Hanson AJ, Bayer-Carter JL, Green PS, Montine TJ, Wilkinson CW, Baker LD, Watson GS, Bonner LM, Callaghan M, Leverenz JB, Tsai E, Postupna N, Zhang J, Lampe J, Craft S (2013) Effect of apolipoprotein E genotype and diet on apolipoprotein E lipidation and amyloid peptides: randomized clinical trial. JAMA Neurol 70:972-980. CrossRef Medline

Harris FM, Brecht WJ, Xu Q, Mahley RW, Huang Y (2004) Increased tau phosphorylation in apolipoprotein E4 transgenic mice is associated with activation of extracellular signal-regulated kinase: modulation by zinc. J Biol Chem 279:44795-44801. CrossRef Medline

He X, Cooley K, Chung CH, Dashti N, Tang J (2007) Apolipoprotein receptor 2 and X11 alpha/beta mediate apolipoprotein E-induced endocytosis of amyloid-beta precursor protein and beta-secretase, leading to amyloidbeta production. J Neurosci 27:4052-4060. CrossRef Medline

Hirsch-Reinshagen V, Zhou S, Burgess BL, Bernier L, McIsaac SA, Chan JY, Tansley GH, Cohn JS, Hayden MR, Wellington CL (2004) Deficiency of ABCA1 impairs apolipoprotein E metabolism in brain. J Biol Chem 279: 41197-41207. CrossRef Medline

Jiang Q, Lee CY, Mandrekar S, Wilkinson B, Cramer P, Zelcer N, Mann K, Lamb B, Willson TM, Collins JL, Richardson JC, Smith JD, Comery TA, Riddell D, Holtzman DM, Tontonoz P, Landreth GE (2008) ApoE promotes the proteolytic degradation of Abeta. Neuron 58:681-693. CrossRef Medline

Kariv-Inbal Z, Yacobson S, Berkecz R, Peter M, Janaky T, Lütjohann D, Broersen LM, Hartmann T, Michaelson DM (2012) The isoformspecific pathological effects of apoE4 in vivo are prevented by a fish oil (DHA) diet and are modified by cholesterol. J Alzheimers Dis 28:667683. CrossRef Medline

Karten B, Campenot RB, Vance DE, Vance JE (2006) Expression of ABCG1, but not $\mathrm{ABCA1}$, correlates with cholesterol release by cerebellar astroglia. J Biol Chem 281:4049-4057. CrossRef Medline

Kim WS, Weickert CS, Garner B (2008) Role of ATP-binding cassette transporters in brain lipid transport and neurological disease. J Neurochem 104:1145-1166. CrossRef Medline

Koldamova RP, Lefterov IM, Staufenbiel M, Wolfe D, Huang S, Glorioso JC, Walter M, Roth MG, Lazo JS (2005) The liver X receptor ligand T0901317 decreases amyloid beta production in vitro and in a mouse model of Alzheimer's disease. J Biol Chem 280:4079-4088. CrossRef Medline

Laffitte BA, Repa JJ, Joseph SB, Wilpitz DC, Kast HR, Mangelsdorf DJ, Tontonoz P (2001) LXRs control lipid-inducible expression of the apolipoprotein E gene in macrophages and adipocytes. Proc Natl Acad Sci U S A 98:507-512. CrossRef Medline

Lalloyer F, Pedersen TA, Gross B, Lestavel S, Yous S, Vallez E, Gustafsson JA, 
Mandrup S, Fiévet C, Staels B, Tailleux A (2009) Rexinoid bexarotene modulates triglyceride but not cholesterol metabolism via gene-specific permissivity of the RXR/LXR heterodimer in the liver. Arterioscler Thromb Vasc Biol 29:1488-1495. CrossRef Medline

Levi O, Michaelson DM (2007) Environmental enrichment stimulates neurogenesis in apolipoprotein E3 and neuronal apoptosis in apolipoprotein E4 transgenic mice. J Neurochem 100:202-210. CrossRef Medline

Levi O, Jongen-Relo AL, Feldon J, Roses AD, Michaelson DM (2003) ApoE4 impairs hippocampal plasticity isoform-specifically and blocks the environmental stimulation of synaptogenesis and memory. Neurobiol Dis 13:273-282. CrossRef Medline

Liang Y, Lin S, Beyer TP, Zhang Y, Wu X, Bales KR, DeMattos RB, May PC, Li SD, Jiang XC, Eacho PI, Cao G, Paul SM (2004) A liver X receptor and retinoid $\mathrm{X}$ receptor heterodimer mediates apolipoprotein E expression, secretion and cholesterol homeostasis in astrocytes. J Neurochem 88:623634. CrossRef Medline

Liraz O, Boehm-Cagan A, Michaelson DM (2013) ApoE4 induces Abeta42, tau, and neuronal pathology in the hippocampus of young targeted replacement apoE4 mice. Mol Neurodegener 8:16. CrossRef Medline

Michikawa M, Fan QW, Isobe I, Yanagisawa K (2000) Apolipoprotein E exhibits isoform-specific promotion of lipid efflux from astrocytes and neurons in culture. J Neurochem 74:1008-1016. CrossRef Medline

Minagawa H, Gong JS, Jung CG, Watanabe A, Lund-Katz S, Phillips MC, Saito H, Michikawa M (2009) Mechanism underlying apolipoprotein E (ApoE) isoform-dependent lipid efflux from neural cells in culture. J Neurosci Res 87:2498-2508. CrossRef Medline

Price AR, Xu G, Siemienski ZB, Smithson LA, Borchelt DR, Golde TE, Felsenstein KM (2013) Comment on "ApoE-directed therapeutics rapidly clear beta-amyloid and reverse deficits in AD mouse models." Science 340:924-d. CrossRef Medline

Puglielli L, Tanzi RE, Kovacs DM (2003) Alzheimer's disease: the cholesterol connection. Nat Neurosci 6:345-351. CrossRef Medline

Riddell DR, Zhou H, Atchison K, Warwick HK, Atkinson PJ, Jefferson J, Xu L, Aschmies S, Kirksey Y, Hu Y, Wagner E, Parratt A, Xu J, Li Z, Zaleska MM, Jacobsen JS, Pangalos MN, Reinhart PH (2008) Impact of apolipoprotein E (ApoE) polymorphism on brain ApoE levels. J Neurosci 28:1144511453. CrossRef Medline

Roses AD (1996) Apolipoprotein E alleles as risk factors in Alzheimer's disease. Annu Rev Med 47:387-400. CrossRef Medline

Salomon-Zimri S, Boehm-Cagan A, Liraz O, Michaelson DM (2014) Hippocampus-related cognitive impairments in young apoE4 targeted replacement mice. Neurodegener Dis 13:86-92. CrossRef Medline

Saunders AM, Strittmatter WJ, Schmechel D, George-Hyslop PH, PericakVance MA, Joo SH, Rosi BL, Gusella JF, Crapper-MacLachlan DR, Alberts MJ, et al. (1993) Association of apolipoprotein E allele epsilon 4 with late-onset familial and sporadic Alzheimer's disease. Neurology 43:14671472. CrossRef Medline

Strittmatter WJ, Saunders AM, Goedert M, Weisgraber KH, Dong LM, Jakes R, Huang DY, Pericak-Vance M, Schmechel D, Roses AD (1994) Isoform-specific interactions of apolipoprotein $\mathrm{E}$ with microtubuleassociated protein tau: implications for Alzheimer disease. Proc Natl Acad Sci U S A 91:11183-11186. CrossRef Medline

Sullivan PM, Mezdour H, Aratani Y, Knouff C, Najib J, Reddick RL, Quarfordt SH, Maeda N (1997) Targeted replacement of the mouse apolipoprotein E gene with the common human APOE3 allele enhances diet-induced hypercholesterolemia and atherosclerosis. J Biol Chem 272:17972-17980. CrossRef Medline

Tai LM, Bilousova T, Jungbauer L, Roeske SK, Youmans KL, Yu C, Poon WW, Cornwell LB, Miller CA, Vinters HV, Van Eldik LJ, Fardo DW, Estus S, Bu G, Gylys KH, Ladu MJ (2013) Levels of soluble apolipoprotein E/amyloid-beta (Abeta) complex are reduced and oligomeric Abeta increased with APOE4 and Alzheimer disease in a transgenic mouse model and human samples. J Biol Chem 288:5914-5926. CrossRef Medline

Tesseur I, Lo AC, Roberfroid A, Dietvorst S, Van Broeck B, Borgers M, Gijsen H, Moechars D, Mercken M, Kemp J, D’Hooge R, De Strooper B (2013) Comment on "ApoE-directed therapeutics rapidly clear beta-amyloid and reverse deficits in AD mouse models." Science 340:924-e. CrossRef Medline

Tokuda T, Calero M, Matsubara E, Vidal R, Kumar A, Permanne B, Zlokovic B, Smith JD, Ladu MJ, Rostagno A, Frangione B, Ghiso J (2000) Lipidation of apolipoprotein E influences its isoform-specific interaction with Alzheimer's amyloid beta peptides. Biochem J 348:359-365. CrossRef Medline

Ulrich JD, Burchett JM, Restivo JL, Schuler DR, Verghese PB, Mahan TE, Landreth GE, Castellano JM, Jiang H, Cirrito JR, Holtzman DM (2013) In vivo measurement of apolipoprotein $\mathrm{E}$ from the brain interstitial fluid using microdialysis. Mol Neurodegener 8:13. CrossRef Medline

Vance JE, Hayashi H (2010) Formation and function of apolipoprotein E-containing lipoproteins in the nervous system. Biochim Biophys Acta 1801:806-818. CrossRef Medline

Veeraraghavalu K, Zhang C, Miller S, Hefendehl JK, Rajapaksha TW, Ulrich J, Jucker M, Holtzman DM, Tanzi RE, Vassar R, Sisodia SS (2013) Comment on "ApoE-directed therapeutics rapidly clear beta-amyloid and reverse deficits in AD mouse models." Science 340:924-f. CrossRef Medline

Wahrle SE, Jiang H, Parsadanian M, Legleiter J, Han X, Fryer JD, Kowalewski T, Holtzman DM (2004) ABCA1 is required for normal central nervous system ApoE levels and for lipidation of astrocyte-secreted apoE. J Biol Chem 279:40987-40993. CrossRef Medline

Whitney KD, Watson MA, Collins JL, Benson WG, Stone TM, Numerick MJ, Tippin TK, Wilson JG, Winegar DA, Kliewer SA (2002) Regulation of cholesterol homeostasis by the liver $\mathrm{X}$ receptors in the central nervous system. Mol Endocrinol 16:1378-1385. Medline

Ye S, Huang Y, Müllendorff K, Dong L, Giedt G, Meng EC, Cohen FE, Kuntz ID, Weisgraber KH, Mahley RW (2005) Apolipoprotein (apo) E4 enhances amyloid beta peptide production in cultured neuronal cells: apoE structure as a potential therapeutic target. Proc Natl Acad Sci U S A 102: 18700-18705. CrossRef Medline

Youmans KL, Tai LM, Nwabuisi-Heath E, Jungbauer L, Kanekiyo T, Gan M, Kim J, Eimer WA, Estus S, Rebeck GW, Weeber EJ, Bu G, Yu C, Ladu MJ (2012) APOE4-specific changes in Abeta accumulation in a new transgenic mouse model of Alzheimer disease. J Biol Chem 287:41774-41786. CrossRef Medline

Zepa L, Frenkel M, Belinson H, Kariv-Inbal Z, Kayed R, Masliah E, Michaelson DM (2011) ApoE4-driven accumulation of intraneuronal oligomerized Abeta42 following activation of the amyloid cascade in vivo is mediated by a gain of function. Int J Alzheimers Dis 2011:792070. CrossRef Medline 